\title{
"We But Had Ta Tough We've Sort of Sewn Our Way Through lt:" The Partnership Quilt
}

Using capacitive touch sensors and traditional quilting techniques lead to the collision of seemingly disparate worlds and resulted in the creation of the Partnership Quilt, a living archive of voices in the shape of an interactive piece of craftwork.

\section{By Angelika Strohmayer and Janis Meissner}

DOI: 10.1145/3155128

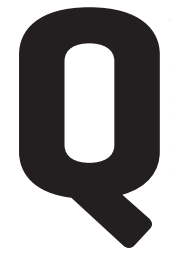
uilting is about making connections and establishing relationships between different parts. The craft process involves sewing several textile layers together to create a thicker padded fabric. However, in the case of our recent involvement in the Partnership Quilt, the connections also emerged on a collaborative level. The collective act of sewing simple rosettes and quilting blocks turned into an interactive piece of art by bringing different and disparate expert knowledge together. We as human computer interaction (HCI) researchers and interaction designers worked alongside the quilting designers from Six Penny Memories, ${ }^{a}$ as well as staff and service users from Changing Lives, ${ }^{\mathrm{b}}$ specifically Girls are Proud (GAP) and the Male Action Project (MAP). Changing Lives is a U.K. based charity focused on

those deemed "vulnerable"-the homeless, people suffering from addiction, and the unemployed. The GAP/MAP projects specifically provide people-focused services to support those engaged in sex work, survival sex, or anyone experiencing sexual exploitation. Through this collaboration,

a https://six-penny.com

b http://www.changing-lives.org.uk we combined elements of social-care practice, professional quilting skills, as well as interaction design tools to produce a living archive of experiences from the women GAP supports, alongside those who support them.

\section{THE FIRST STITCH}

The quilt is contextualized in local histories of craft and women's work. Quilting used to be something that was taught in schools in the North East of England, and many of those who put a stitch in the quilt had previously done this in their childhood, but the type of teaching they spoke of rarely happens anymore. Many different techniques were used to construct the quilt, such as English paper-piecing, applique, machine-quilting, and tiequilting. Using these traditional techniques, the women "[were] carrying on 


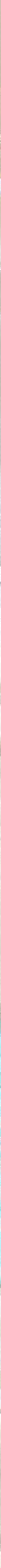




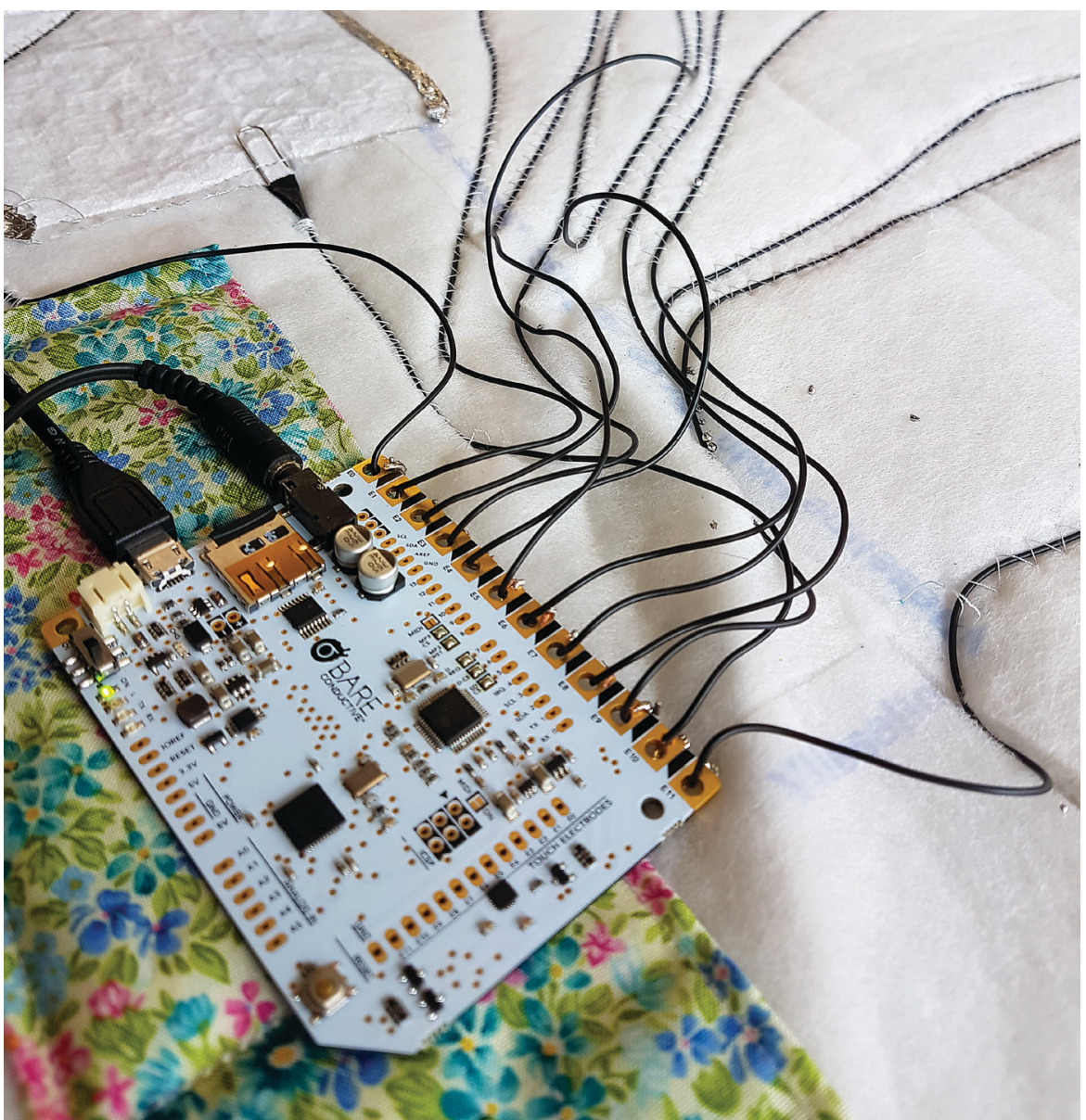

a tradition that's particularly popular in this area."

We introduced the idea of turning the quilt blocks into capacitive touch sensors to be able to share experiences of making the quilt with others who interact with it. One of our goals in our overall work is to alleviate stigma in stigmatized groups. People engaged in sex work are often stigmatized. Through the quilt project, it's process and outcomes, we hoped to work toward advocacy tools to reduce stigma (e.g. public exhibitions of the quilt) and share personal well-being strategies focused on self care (e.g. sewing). Almost simultaneously, Six Penny Memories were introduced to the project. They are a duo of professional quilters and designers who have written several books, appeared on quilting TV, and have authored hundreds of quilting patterns.

\section{PUTTING THE PIECES TOGETHER}

We organized two days to come together as part of what we called "Quilting Extravaganzas" to sew fabric hexagons together and tie-quilt, solder, and attach the layer of low-cost DIY capacitive touch sensors to the traditional quilt. After which, we audio-recorded a group reflection on the creation process and our feelings toward the quilt made up of the voices of many of those who partook in the creation of it. This recording was later edited into 12 individual audio clips that were then transferred to the quilt.

Following these days, we visited the quilting shop from where Six Penny Memories work to witness how they integrated their traditional skills into the digital layer of the quilt. Six Penny Memories were able to quilt the sensors we made from tinfoil and wires soldered to paper onto the fabric, and attached a small pocket as the new home for the BARE Conductive Touchboard (a commercial microcontroller specialized for capacitive touch sensing). A week later, the charity staff and women from GAP also visited the shop to explore the audio-recordings triggered by interacting with the finished quilt.

In the end, the quilt was construct- ed by a group of women over what ended up being roughly one year. It consisted of various phases that were carried out during drop-in sessions, two days of work during the Quilting Extravaganzas, and work carried out by individuals in their respective homes and/or workspaces. The entire project included: (1) the sewing of individual rosettes; (2) the appliquéing of these rosettes onto a background fabric; (3) the joining up of these squares and machine quilting to place the backing, wadding, and the quilt top; (4) the creation of the quilted layer of capacitive touch sensors and tie-quilting of the traditional quilt; (5) the attaching of the Touchboard with the embedded audiofiles from the reflection; and (6) the edging of both quilts. To be able to go through each of these six stages of the production of the quilt, "we all used our own little bits of knowledge," but ultimately as one case worker put it, you "just need a little squad of women, and you can get so much done."

Once the quilt was nearing its last stages during the second Quilting Extravaganza, we sat around a large table, the quilt laid out in front of us, and a cup of tea in hand, to marvel at our accomplishment and reflect on what we had done. It was here we recorded a roughly 30 -minute discussion of many of those involved in the quilt. During this discussion, we reflected with many different aspects of the quilt such as the history of it, the techniques used, as well as the different experiences we had in the crafting of it. One of the women who produced many of the rosettes said one of her sons had taken two rosettes that she had sewn together and placed them on his pillow at night. The group encouraged her to sew them onto his pillow, to which she responded: "He won't let us! He carries them around everywhere. They go in his pocket, in his school bag, he just carries them everywhere." Another woman stated the quilt "needs to be used, doesn't it?", urging us all to continue to interact with it.

Twelve extracts from the recordings were cureated to be shared with the wider public through the touch interaction on the quilt: When one of the rosettes on the quilt is touched, one of the audio files starts to play. Four of 
these extracts contextualize the quilt historically, six discuss the making of the quilt, and two address some of the outcomes that we have either already achieved or hope to achieve in the near future with the quilt.

Since then, the quilt has been exhibited at the Vlieseline stall at the Festival of Quilts in Birmingham, UK. On top of exhibiting the quilt for amateur and professional quilters at the Festival of Quilts we are also working on exhibiting it in a venue closer to those who put a stitch in it so they can go to take their friends and family to see the work they have done. Furthermore, the charity aims to use the quilt not only for public education at these private, public, or semi-public exhibitions, but also as a continued form of service delivery. Since we used a combination of DIY sensors and the out-of-the-box touch board, it is quite simple to change the audio files that are triggered through the touch of a rosette; to transform the interactive piece of art into a living archive of voices of those involved in the process. As such, charity staff are keen to explore different ways in which the recording of audio and interactions with the quilt could be used for staff and volunteer training, one-on-one reflection with clients, or the sharing of their services with other charities and members of the general public.

\section{REFLECTING ON THE QUILT}

While the quilt is being used in exhibitions and will be used for training and reflexive purposes in the future, we want to sidestep to reflect a little bit on the quilt as an object, as well as the process behind the making of it. Just like the layers of fabric and wadding that are in the quilt, it has layers of stories and experiences meticulously sewn into it with each stitch and button.

The quilt was a chance for the local women to sit together quietly during the drop-in session, while carrying out an activity. It was, however, also an opportunity for people to stay in touch after these drop-ins. The first Quilting Extravaganza day took place more than month after the caseworker who had been a driving force in starting the project was moved to work at a different drop-in center. As such, the day was a chance for the case worker and those women to continue to be engaged with each other despite the changes; the case worker said, "It's nice to be able to get back into this project [...] it's the first time I've seen these lasses in more than a month because I no longer work at their drop-in." This sentiment continued at the second Quilting Extravaganza a month later: "This quilt has almost been a little community link for us that's kept us together," explained one of the women.

Not only has the quilting project provided a space for social interaction, but it was also an opportunity for learning new skills. By taking part in the entire process, everyone involved in the project went through the entire process of designing and sewing quilting blocks, as well as quilting the various layers of the blanket together. On top of these traditional skills, the process of creating, wiring, and attaching DIY capacitive touch sensors to fabric were also mastered by those involved. Another caseworker, who had heard a lot about the quilt in the office, supported the project by making blocks at the drop-in center she's responsible for. Without ever having seen the quilt before, she responded very emotionally when the artifact was finally in front of her. As she struggled to find the right words, she concluded: "I feel a bit like, wowed. Is that the word? Like, like what you've just said. Getting a group of lasses together [...] I don't think the GAP and MAP projects ever come up with anything like this. Like, creative, in such a long time!"

While there are a few very tangible skills involved in the process of making the quilt that those involved learned, it also supported the women emotionally. This can be seen in the following extract from our collective reflection from when we were nearing the end of the project:

Caseworker: "I bet [the sewing] chilled you out a bit..."

GAP client: "It did, "cause at the time I refused medication as well, so [...] it was the only thing I focused on. 'Cause all the other stuff was negative, and that was positive."

On top of these personal experiences of making the quilt and the emotions toward it, it was also seen as an example of what can be achieved for a drop-in on a broader level. Dropins are a common type of service delivery promoted by sex work support services and other charities. They are sessions that take place regularly, and for one of the women who took part in the drop-in where the quilt was developed, the drop-in is an opportunity for "just having a laugh and that" or an opportunity for some fun. As one woman explained, "to get out and, just for a couple of hours, yea, those couple of hours do go fast don't they?" Although drop-ins are usually not targeted toward a long-term goal, this particular drop-in started to revolve around the quilt. Each session, the women would sit together to sew some rosettes for the quilt. Initially, they were sewing simply for the purpose of sewing, for the mindfulness involved in the activity: "When we first started to make the quilt I didn't think we'd ever get to this far. To this thing," another shared. However, as the project continued to progress, and when Six Penny Memories and Open Lab became involved, the quilt started to become a more tangible goal to work toward; something to be proud of.

In the end the quilt was a chance for people to come together to work on something collaboratively and creatively, while simultaneously having a space for individual, mindful practice. A case worker sums the concoction of emotions, craft, and collaboration that went into the process, outcome, and continued use of the Partnership Quilt as something that helped: "[We] keep werselves busy, we've kept ourselves out of trouble, and I've got some lovely memories sitting with youse."

\footnotetext{
Biographies

Angelika Strohmayer is a Ph.D. student in the Centre for Doctoral Training in Digital Civics at Open Lab, Newcastle University. She is interested in the ways in which digital technologies can be designed for support services to aid their service delivery while simultaneously being useful for advocacy work and the sex worker rights movement.

Janis Meissner is also a Ph.D. student in the Centre for Doctoral Training in Digital Civics at Open Lab, Newcastle University. As maker technologies give individuals an opportunity to develop their own objects and tools, Janis is interested in exploring the ways in which these technologies can empower different communities. $1529-4972 / 17 / 12$
} 